\title{
Improving beetle karyotype analysis: restriction endonuclease banding of Tenebrio molitor chromosomes
}

\author{
C. Juan*市 \\ J. Gosálvez† \\ E. Petitpierre $\ddagger$
}

$\dagger$ Unidad de Genética. Departamento de Biología. C-XV, Facultad de Ciencias, Universidad Autónoma de Madrid, Spain.

$\ddagger$ Laboratori de Genètica. Departament de Biologia i C.S., Facultat de Ciències, Universitat de les Illes Balears, 07071 Palma de Mallorca, Spain.

Fixed mitotic chromosomes of Tenebrio molitor have been analysed by means of $\mathbf{C}$-banding and by digestion with EcoRI and AluI restriction endonucleases. The chromosomal morphology, ambiguous after conventional staining or C-banding, is much improved by digestion with restriction endonucleases. AluI gives a banding pattern similar to that obtained by C-banding, while EcoRI induces a reverse banding pattern with respect to the previous ones. The EcoRI digestion pattern of chromosomes is probably produced by extraction of a pericentromeric and equilocated highly repeated DNA. In this species, it seems that neither the compaction of the heterochromatin nor the size of the restriction target (six base pairs (bp) for EcoRI) have any effect on the amount of removable DNA. Also, a chromosomal heteromorphism for pair number 9 due to a pericentric inversion has been found in one individual by means of EcoRI treatment, that was cryptic by the other banding techniques.

\section{INTRODUCTION}

In the last 20 years banding techniques have provided an important tool for either the study of chromosome structure and/or identification of individual chromosomes. Recently, restriction endonucleases (RE) have been used to induce chromosome banding by in situ digestion of fixed chromatin in a large variety of organisms (Bianchi and Bianchi, 1987; López-Fernández et al., 1989), and these simple techniques are very useful for detection of specific sequences of DNA, such as for example satellite DNAs (Mezzanotte et al., 1986) or regions which remains cryptic with other banding techniques (Gosálvez et al., 1987; 1989). Miller et al. (1983) suggested that the bands produced by restriction enzymes could also be very useful to disentangle the karyotype of organisms that lack easily banded chromosomes, such as amphibians, fishes or some plants. In all these cases a useful level of resolution has been obtained after RE-banding (Schmid and Almeida, 1988; Lloyd and Thorgaard, 1988; Frediani et al., 1987), respectively.

* Present address: School of Biological Sciences, University of East Anglia, Norwich NR4 7TJ, U.K.
In coleopterans there are relatively few reports of chromosome banding (Ennis, 1974; Angus, 1983; Virkki and Denton, 1987; Juan and Petitpierre, 1989), probably because of the small size of their chromosomes and the poor resolution of longitudinal differentiation obtained with conventional techniques. In most cases, the individual identification of all chromosomes is difficult due to the similarities of size and shape. The chromosomes of the mealworm beetle Tenebrio molitor are no exception. This species has very similar chromosomes except for the minute $Y$ chromosome, which show very large heterochromatic blocks after Cbanding (Weith, 1985; Juan and Petitpierre, 1989). The large amount of heterochromatin present in each centromere region has been used for two different purposes: (i) comparison under electron microscopy of the euchromatin and constitutive heterochromatin structure (Weith, 1983, 1985) and (ii) characterization by agarose gel electrophoresis of EcoRI restriction digests and sequencing the satellite DNA thought to be localized in these regions (Petitpierre et al., 1988; Davis and Wyatt, 1989).

The aim of this study is to investigate the action of different REs on the chromosomes of this organism, in an attempt to improve the resolution of 


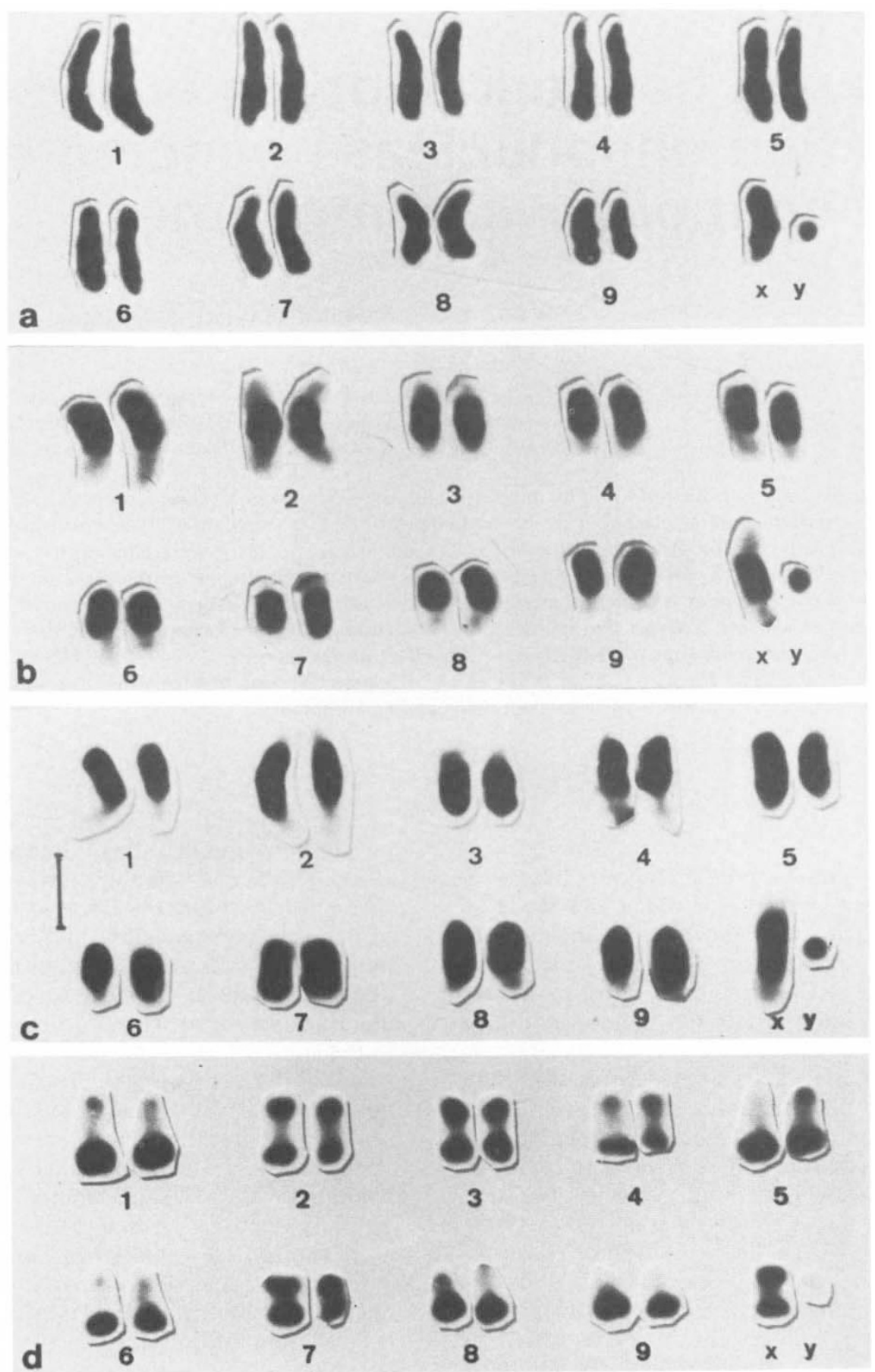

Figure 1 (a) T. molitor male karyotype with Giemsa staining. (b) C-banded karyotype. Banding patterns produced after digestion with $A l u I$ (c) and with Eco RI (d) restriction endonucleases. Bar, $5 \mu \mathrm{m}$. 
bands produced with other methods. This approach can help obtain a better knowledge of Tenebrio molitor karyotype for analysing polymorphisms and polytypisms of evolutionary interest and also be useful in analysing the structural characteristics of the huge amount of heterochromatin present in this organism.

\section{MATERIAL AND METHODS}

\section{Chromosome preparations}

Animals were obtained from a commercial dealer and from a laboratory strain (C.S.I.C, Barcelona). Male larvae from the third instar were killed and their gonads dissected out. The gonadal tissue was immersed in a 0.05 per cent colchicine solution for $1 \mathrm{~h}$, hypotonically treated in $0.075 \mathrm{M} \mathrm{KCl}$ for 5 min and fixed in fresh ethanol-acetic solution $(3: 1)$. Then, the gonads were squashed in 45 per cent acetic acid, the slides frozen in liquid nitrogen and the coverslips removed by a fine razor blade.

\section{Banding procedures}

Fresh preparations were digested with 50-100 units of either Eco RI or AluI (Boehringer-Mannheim) in $100 \mu \mathrm{l}$ of the appropriate buffer and evenly spread over the slide by means of a coverslip. The digestions were carried out at $37^{\circ} \mathrm{C}$ overnight. After that, the preparations were washed with distilled water and stained with 2 per cent Giemsa in phosphate buffer ( $p H$ 6.8). Control digestions with the buffers only were also undertaken. Conventional C-banding (Sumner, 1972) and Giemsa staining were also performed.

\section{RESULTS}

Fig. 1(a) shows the karyotype of $T$. molitor, with meta- and submetacentric chromosomes decreasing somewhat in size. The $\mathrm{X}$-chromosome is a medium-sized, submetacentric and the $\mathrm{Y}$ a dot-like chromosome. Constitutive heterochromatin revealed by $\mathrm{C}$-banding occupies extensive blocks apparently localized in the pericentromeric regions of all chromosomes (fig. 1(b)). In five pairs the $\mathrm{C}$-bands are distal and in four pairs and the $\mathrm{X}$ chromosome they are in the middle of the chromosome. The Y-chromosome appears entirely heterochromatic.

When the $T$. molitor chromosomes are treated with $A l u \mathrm{I}$, they show a C-like banding pattern with prominent heterochromatic blocks in each auto- some and sex chromosome. The distal parts of most chromosomal arms appear faintly stained (fig. 1(c)). The reverse is seen when treated with EcoRI, they exhibited median and distal regions that stain slightly with Giemsa (fig. 1(d)). These regions correspond well with those positive to $\mathrm{C}$ bands/AluI bands. In fact, the banding pattern obtained with Eco RI is like a reverse C-banding.

The digestion of fixed chromosomes with EcoRI provides a very good resolution on mitotic metaphsase plates, which is better than that obtained with other banding techniques, including different combinations of specific fluorescent ligands such as chromomycin $\mathrm{A}_{3}$ or diamidinophenylindol (DAPI) (not shown, Juan et al., in preparation). The use of EcoRI uncovered a polymorphism for chromosome 9 which is cryptic with other banding techniques. Indeed, with $A l u \mathrm{I}$ or C-banding the faint staining of the distal euchromatin does not permit identification of such rearrangements. One out of four individuals studied had an heteromorphic 9-chromosome pair formed by an acrocentric plus a metacentric chromosome (fig. 2).

\section{DISCUSSION}

The in situ digestion of fixed chromosomes with REs in T. molitor provides an excellent tool to identify each chromosome pair, better than Cbanding or other techniques, opening the way for karyological studies in these organisms with small chromosomes. We have now consistent data which show that the clear chromosome morphology after digestion with EcoRI is closely related to the particular structure of the satellite DNA localized in the heterochromatic regions of $T$. molitor. We will deal fully in the biochemical and cytological details in a separate paper (Juan et al., in preparation). In the genus Tribolium, belonging to the same family, Smith (1952) described heterochromatic blocks in all pachytene bivalents by observation of male meiosis. Petitpierre et al. (1988) pointed out that there is a large amount of a satellite DNA in $T$. molitor, almost 50 per cent of the whole genome. This satellite is rather rich in AT base pairs (61 per cent). Therefore, chromomycin $A_{3}$ (a flurochrome which binds preferentially to GC-rich DNAs) gives rise to dull fluorescence in heterochromatin. In any event, the level of contrast between eu- and heterochromatin is not as good as that obtained with EcoRI. The homogenous digestion $(E c o \mathrm{RI})$ or null digestion $(A l u \mathrm{I})$ as well as the evenness of fluorescence with $\mathrm{CMA}_{3}$ or 


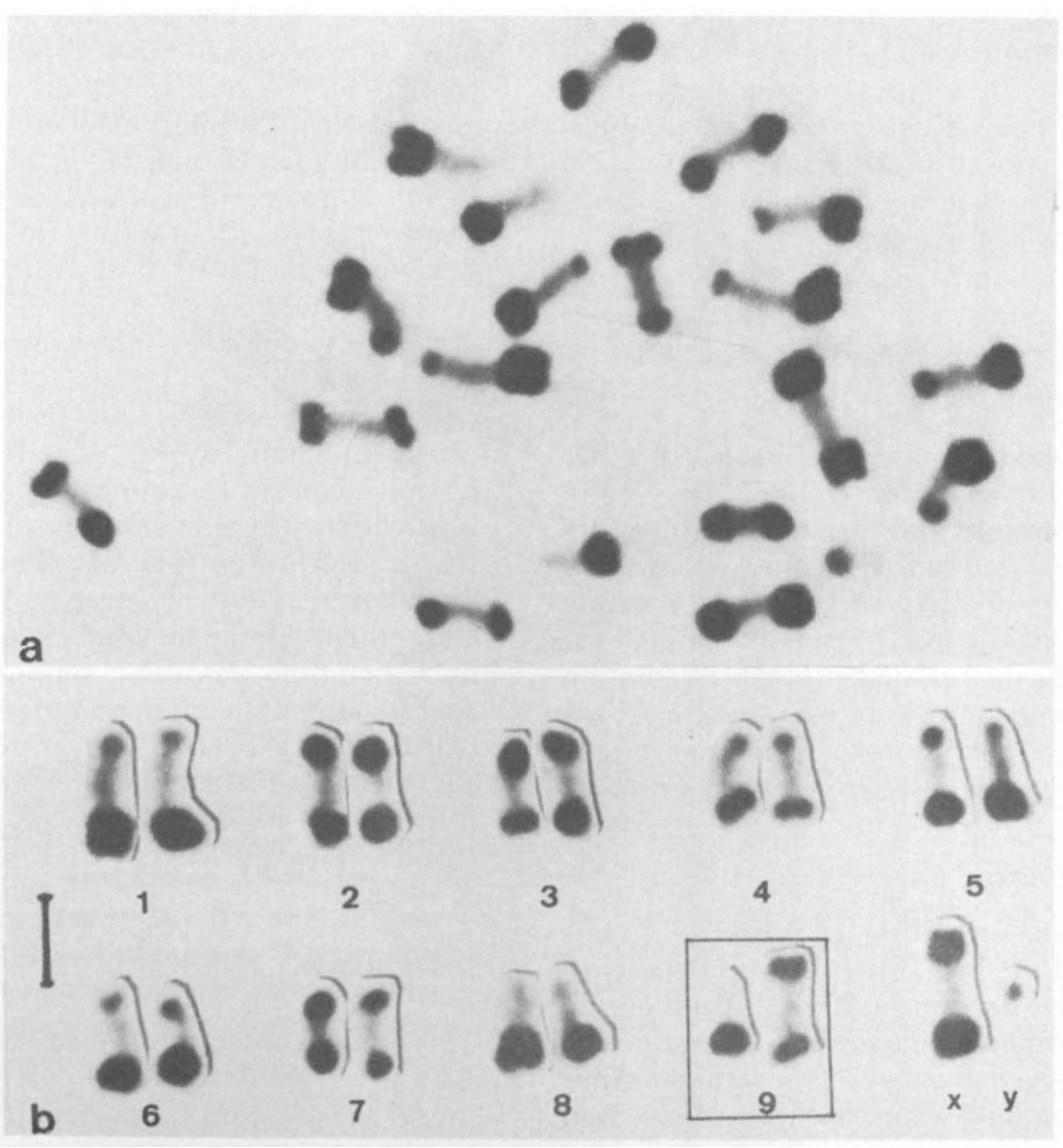

Figure 2 EcoRI digested spermatogonial metaphase (a) and karyotype (b) of one individual with a chromosome heteromorphism in pair number 9 Bar $5 \mu \mathrm{m}$.

DAPI in every centromere region, point to an equilocal distribution of heterochromatin throughout all the genome of $T$. molitor such as has been reported in other organisms (Schweizer et al., 1987; John et al., 1985). This homogenous distribution also involves the Y-chromosome which is entirely heterochromatic and entirely digested by EcoRI. This heterochromatic homogeneity in $T$. molitor is similar to that found in mouse chromosomes (Pardue \& Gall, 1970; Kaelbling et al., 1984; Mezzanotte \& Ferrucci, 1984) and contrasts with other species where REs have shown a remarkable heterochromatic heterogeneity (Gosálvez et al., 1987; LópezFernández et al., 1989).

Among a series of factors which may affect the cleavage of fixed chromatin by a RE (Bianchi et al., 1985; Mezzanotte et al., 1985; Gosálvez et al., 1989), it has been extensively claimed that the compaction of the heterochromatin and the size of the restriction target are important factors in determining the amount of removable DNA (Miller et al., 1983; Mezzanotte et al., 1983, 1985; Bianchi et al., 1985). The results obtained with EcoRI show, at least in this species, that both factors are irrelevant to RE-cleavage and subsequent DNA-removal. Cases of extensive cleavage of heterochromatic regions have been reported in different organisms. For example, $A l u \mathrm{I}$ in the grasshopper Pyrgomorpha conica removes the centromeric DNA of all chromosomes both in mitosis and meiosis (López-Fernández et al., 1989). In mouse AvaII (GG $\mathrm{G}_{\mathrm{T}}^{\mathrm{A}} \mathrm{CC}$ ) and Bst NI ( $\left.\mathrm{CC}_{\mathrm{T}}^{\mathrm{A}} \mathrm{GG}\right)$ reduce the staining of most of the centromeres (Kaelbling et al., 1984), although in this case, the results of Bst NI appears contradictory to those reported by Burkholder (1989). In general, four base pair cutters are more efficient in removing 
large amounts of DNA, while five or six base pair cutters usually do not produce longitudinal differentiation or give G bands (Mezzanotte et al., 1985; López-Fernández et al., 1989). Indeed this is the first case reported where a six base pair cutter $(E c o \mathrm{RI})$ produce a dramatic decrease in the staining of a heterochromatic region.

The Eco RI banding in T. molitor has allowed us to find a hetermorphism for a chromosome pair (pair number 9), probably caused by a pericentric inversion, according to the similar sizes of the EcoRI resistant chromatin in both the standard and the rearranged chromosome. Pericentric inversions have often been hypothesized as one of the most important structural rearrangements in coleopteran chromosomes, but are poorly demonstrated because of the limited resolution of conventional staining techniques. Such rearrangements have been claimed in some species of Cicindelidae (Serrano, 1981), Scarabaeidae (Virkki, 1967), Chrysomelidae (Petitpierre, 1983; Hsiao and Hsiao, 1983), among others. Moreover, it has been supposed that centric fissions in metacentric chromosomes were followed by pericentric inversions or heterochromatin accretions, restoring the metacentric shape that prevails in coleopteran chromosomes (Smith and Virkki, 1978). We think these techniques may be used to throw some light on the real role that these rearrangements have in the divergence of closely related taxa.

Acknowledgments We would like to thank Professor R. Mezzanotte for discussions to improve the manuscript and to $\mathrm{Dr}$ $\mathrm{X}$. Bellés for kindly providing a $T$. molitor culture. This work has been supported by Projects of DGICYT no. PB87-0584C02-01 and PB86/0107 (Spain)

\section{REFERENCES}

ANGUS, R. B. 1983. Separation of Helophorus grandis, maritimus and occidentalis sp. (Coleoptera, Hydrophilidae) by banded chromosome analysis. Syst. Ent. 8, 1-13.

BIANCHI, M. S., BIANCHI, N. O., PANTELIAS, G. E. AND WOLFF, S. 1985. The mechanism and pattern of banding induced by restriction endonucleases in human chromosomes. Chromosoma, 91, 131-136.

BIANCHI, N. O. AND BIANCHI, M. S. 1987. Analysis of the Eukaryotic chromosome organization with restriction endonucleases. In Obe, G. and Barler, A. (eds) Cytogenetics, Springer-Verlag, Berlin, pp 226-280.

BURKHOLDER, G. D. 1989. Morphological and biochemical effects of endonucleases on isolated mammalian chromosomes in vitro. Chromosoma, 97, 347-355.

DAVIS, C. A. AND WYATT, G. R. 1989. Distribution and sequence homogeneity of an abundant satellite DNA in the beetle, Tenebrio molitor. Nucleic Acids Res., 17, 5579-5586.
ENNIS, T. J. 1974. Chromosome structure in Chilocorus (Coleoptera, Coccinaelidae). I. Fluorescent and Giemsa banding patterns. Can. J. Genet. Cytol., 16, 651.

FREDIANI, M., MEZZANOTTE, R., VANNI, R., PIGNONE, D. AND CREMONINI, R. 1987. The biochemical and cytological characterization of Vicia fava DNA by mean of Mbo I, Alu I and Bam HI restriction endonucleases. Theor. appl. Genet., 75, 46-50.

GOSALVEZ, J., BELLA, J. L., LOPEZ-FERNANDEZ, C. AND MEZZANOTTE, R. 1987. Correlation between constitutive heterochromatin and restriction enzyme resistant chromatin in Arcyptera tornosi (Orthoptera). Heredity, 59, 173-180.

GOSALVEZ, J., LOPEZ-FERNANDEZ, C., FERRUCCI, L. AND MEZZA NOTTE, R. 1989. DNA base sequence is not the only factor for restriction endonuclease activity on metaphase chromosomes: evidence using isoschizomers. Cytogenet, Cell Genet., 50, 142-144.

HSIAO, T. H. AND HSIAO, C. 1983. Chromosomal analysis of Leptinotarsa and Labidomera beetles (Coleoptera: Chrysomelidae). Genetica, 60, 139-150.

JOHN, B., KING, M., SCHWEIZER, D. AND MENDELAK, M. 1985. Equilocality of heterochromatin distribution and heterochromatin heterogeneity in acridoid grasshoppers. Chromosoma, 91, 185-200.

JUAN, C. AND PETITPIERRE, E. 1989. C-banding and DNA content of seven species of Tenebrionidae (Coleoptera). Genome, 32, 834-839.

KAELblinG, M., MilleR, D. A. AND MilleR, O. J. 1984. Restriction enzymes banding of mouse metaphase chromosomes. Chromosoma, 90, 128-132.

LLOYD, M. A. AND THORGAARD, G. H. 1988. Restriction endonuclease banding of rainbow trout chromosomes. Chromosoma, 96, 171-177.

LOPEZ-FERNANDEZ, C., GOSALVEZ, J, BELLA, J. L., DE LA TORRE, J. AND MEZZANOTTE, R. 1989. Utilización de las endonucleasas de restricción en el análisis del genoma eucarionte. In Genética. Contribuciones de la Genética española en homenaje al profesor Sañudo, Fundación Ramón Areces. Madrid, pp. 131-149.

MEZZANOTTE, R., FERRUCCI, I. L., VANNI, R. AND BIANCHI, V. 1983. Selective digestion of human metaphase chromosomes by Alu I restriction endonuclease. J. Histochem, Cytochem., 31, 553-556.

MEZZANOTTE, R. AND FERRUCCI, L. 1984. Alterations induced in mouse chromosomes by restriction endonucleases. Genetica, 64, 123-128.

MEZZANOTTE, R., FERRUCCI, L., VANNI, R., AND SUMNER, A. T. 1985. Some factors affecting the action of restriction endonucleases on human metaphase chromosomes. Expl. Cell Res. 161, 247-253.

MEZZANOTTE, R., MANCONI, P. E. AND FERRUCCI, L. 1986. On the possibility of localizing in situ Mus musculus and Drosophila virilis satellite DNAs by AluI and Eco RI restriction endonucleases. Genetica, 70, 107-111.

MILlER, D. A., CHOI, Y. C. AND MILLER, O. J. 1983. Chromosome localization of highly repetitive human DNA and amplified ribosomal DNA with restriction enzymes. Science, 219, 395-397.

PARDUE, M. L. AND GALL, J. G. 1970. Chromosomal localization of mouse satellite DNA. Science, 168, 1356-1358.

PETITPIERRE, E. 1983. Karyometric differences among nine species of the genus Chrysolina. Can. J. Genet. Cytol., 25, 33-39.

PETITPIERRE, E., GATEWOOD, J. AND SCHMID, C. W. 1988. Satellite DNA from the mealworm beetle Tenebrio molitor. Experientia, 44, 498-499. 
SCHMID, M. AND ALMEIDA, C. G. 1988. Chromosome banding in Amphibia XII. Restriction endonuclease banding. Chromosoma, 96, 283-290.

SCHWEIZER, D., LOIDL, J., HAMILTON, B. 1987. Heterochromatin and the phenomen of chromosome banding. In Henning, W. (ed.) Results and Function of Eukaryotic Chromosomes Springer-Verlag, Berlin, pp. 235-254.

SERRANO, J. 1981. Chromosome number and karyotypic evolution of Caraboidea. Genetica, 55, 51-60.

SMITH, S. G. 1952. The evolution of heterochromatin in the genus Tribolium (Tenebrionidae: Coleoptera). Chromosoma, 4, 585-610.

SMITH, S. G. AND VIRKKI, N. 1978. Coleoptera. In John, B. (ed.) Animal Cytogenetics 3. Insecta 5, Gebruder Borntraeger, Berlin, 336pp.
SUMNER, A. T. 1972. A simple technique for demonstrating centromeric heterochromatin. Expl. Cell Res., 75, 304-306.

VIRKKI, N. 1967. Chromosome relationships in some North American Scarabaeoid beetles with special reference to Pleocoma and Trox Can. J. Genet. Cytol., 9, 107-125.

VIRKKI, N. AND DENTON, A. 1987. Silver staining of the elements of spermatogenesis in Oedionychina (Chrysomelidae: Alticinae). Hereditas, 106, 37-49.

WEITH, A. 1983 . $\mathrm{Mg}^{2+}$-dependent compactness of heterochromatin chromosome segments. Expl Cell Res., 146, 199203.

WEITH, A. 1985. The fine structure of euchromatin and centromeric heterochromatin in Tenebrio molitor Chromosomes. Chromosoma, 91, 287-296. 